\title{
Choosing between percutaneous coronary intervention and coronary artery bypass graft surgery for nondiabetic patients with multivessel disease
}

\author{
Aeshita Dwivedi, Sripal Bangalore \\ Leon H. Charney Division of Cardiology, Department of Medicine, New York University Langone Medical Center, New York, USA \\ Correspondence to: Sripal Bangalore, MD, MHA, FACC, FAHA, FSCAI. Cardiovascular Clinical Research Center, New York University School of \\ Medicine, 530 First Ave, SKI-9R/109, New York, USA. Email: sripalbangalore@gmail.com.
}

Submitted Oct 14, 2016. Accepted for publication Oct 21, 2016.

doi: $10.21037 /$ jtd.2016.11.104

View this article at: http://dx.doi.org/10.21037/jtd.2016.11.104

Approximately $30-60 \%$ of patients with acute coronary syndrome present with multiple significant coronary lesions and patients with multivessel CAD have worse prognosis including significant increase in death or MI when compared with patients with single vessel CAD (1). Similarly, in patients with stable ischemic heart disease, multivessel CAD portends worse prognosis when compared with patients with single vessel CAD (2).

The treatment of multivessel CAD includes contemporaneous medical therapy with or without revascularization (3). While revascularization improves prognosis in patients with acute coronary syndromes (4), the benefit of routine revascularization for reducing myocardial infarction and all-cause mortality in patients with stable CAD remains controversial (5-7). In symptomatic patients, revascularization provides for more rapid relief of angina (8). Coronary artery bypass graft (CABG) surgery, percutaneous coronary intervention (PCI) or hybrid coronary revascularization are options for revascularization in patients with $\mathrm{CAD}$ (Table 1). While in the diabetic population CABG has been shown to have superior clinical outcomes compared to PCI in a recent randomized trial (9), the optimal revascularization strategy in nondiabetics remains controversial.

To address this question, Chang et al. (10) performed a patient level pooled analysis from the SYNTAX (Synergy between PCI with Taxus and Cardiac Surgery) (11) and the BEST (Randomized Comparison of Coronary Artery Bypass Surgery and Everolimus-Eluting Stent Implantation in the Treatment of Patients with Multivessel Coronary Artery Disease) trials (12), and evaluated the effects of CABG versus PCI with drug eluting stents (DES) on the long-term mortality in nondiabetics with multivessel disease. The primary end point was death from any cause. The secondary outcomes were a composite of death, myocardial infarction, or stroke; myocardial infarction; stroke; or any repeat revascularization.

The SYNTAX trial was a prospective, multicenter, randomized controlled trial, which evaluated the comparative efficacy of CABG versus PCI with Taxus stent among patients with triple vessel disease and or left main disease (11). The trial had a power of $96 \%$ to show non-inferiority between PCI and CABG for the primary end point of MACCE (composite of all-cause death, MI, stroke or repeat revascularization), assuming a 12-month MACCE of $13.2 \%$ for CABG and $14 \%$ for PCI, with a sample size of 1,800 patients. At 12 months, the achieved event rate for MACCE was significantly lower with CABG (12.4\%) when compared with PCI (17.8\%) driven by significant reduction in repeat revascularization. These results were sustained out to 5 -years (event rates $26.9 \%$ vs. $37.3 \% ; \mathrm{P}<0.001$ ). However, the trial was not powered for the endpoint of death. There was no difference in the endpoint of death between PCI and CABG at 1 year (event rates $4.4 \%$ vs. $3.5 \%$; $\mathrm{P}=0.37$ ) or at 5 -year (event rates $13.9 \%$ vs. $11.4 \% ; \mathrm{P}=0.10$ ). The strengths of the trial are enrollment of the target sample size, adequate power for MACCE, and high usage of arterial grafts in the CABG group with $97.3 \%$ receiving at least one arterial graft and $95.6 \%$ receiving an arterial graft to the left anterior descending artery. The limitations are the lower rates of complete revascularization with PCI when compared with CABG (56.7\% vs. $63.2 \%$; $\mathrm{P}=0.005)$ and use of the Taxus stent, which is considered inferior to current 
Table 1 Indications for revascularization in multivessel coronary artery disease per the American College of Cardiology/American Heart Association guidelines

\begin{tabular}{|c|c|c|}
\hline Anatomic setting & Current official recommendation & LOE \\
\hline $\mathrm{CABG}$ and $\mathrm{PCl}$ & I-Heart team approach recommended & $\mathrm{C}$ \\
\hline $\mathrm{CABG}$ and $\mathrm{PCl}$ & Ila-Calculation of STS or SYNTAX scored & B \\
\hline \multicolumn{3}{|c|}{ Unprotected left main } \\
\hline \multirow[t]{3}{*}{$\mathrm{PCl}$} & $\begin{array}{l}\text { Ila-For SIDH when both of the following are present } \\
\text { - Anatomic condition associated with low risk of PCI procedural complications and a high likelihood of } \\
\text { good long term outcome (e.g., low SYNTAX score } \leq 22 \text {, ostial or trunk left main CAD); } \\
\text { - Clinical characteristics that predict a significantly increased risk of adverse surgical outcomes (e.g., } \\
\text { STS predicted risk of operative mortality } \geq 5 \% \text { ) }\end{array}$ & B \\
\hline & $\begin{array}{l}\text { IIb-For SIHD when both of the following are present: } \\
\text { - Anatomic conditions associated with a low to intermediate risk of PCI procedural complications and } \\
\text { an intermediate to high likelihood of good long-term outcome (e.g., low intermediate SYNTAX score of } \\
<33 \text {, bifurcation left main CAD; } \\
\text { - Clinical characteristics that predict an increased risk of adverse surgical outcomes (e.g., moderate-severe } \\
\text { COPD, disability from prior stroke, or prior cardiac surgery. STS predicted risk of operative mortality }>2 \% \text { ) }\end{array}$ & B \\
\hline & III: Harm-For SIHD in patients with unfavorable anatomy for PCI and who are good candidates for CABG & B \\
\hline \multicolumn{3}{|c|}{ 3-vessel disease with or without proximal LAD artery disease* } \\
\hline CABG & I & B \\
\hline $\mathrm{PCl}$ & $\mathrm{llb}$-Of uncertain benefit & B \\
\hline \multicolumn{3}{|c|}{ 2-vessel disease without proximal LAD disease* } \\
\hline \multirow[t]{3}{*}{ CABG } & Ila-With extensive ischemia & B \\
\hline & $\mathrm{Ilb}$-Of uncertain benefit without extensive ischemia & C \\
\hline & $\mathrm{llb}$-Of uncertain benefit & B \\
\hline \multicolumn{3}{|c|}{ 1-vessel proximal LAD artery disease } \\
\hline CABG & Ila-With LIMA for long term benefit & $\mathrm{B}$ \\
\hline $\mathrm{PCl}$ & $\mathrm{Ilb}-$ Of uncertain benefit & $\mathrm{B}$ \\
\hline
\end{tabular}

Table 1 (continued) 
Table 1 (continued)

\begin{tabular}{|c|c|c|}
\hline Anatomic setting & Current official recommendation & LOE \\
\hline CABG & III: Harm & $\mathrm{B}$ \\
\hline $\mathrm{PCl}$ & III: Harm & $\mathrm{B}$ \\
\hline \multicolumn{3}{|l|}{ LV dysfunction } \\
\hline CABG & Ilb $-E F<35 \%$ without significant left main $C A D$ & $\mathrm{~B}$ \\
\hline $\mathrm{PCl}$ & Insufficient data & \\
\hline \multicolumn{3}{|c|}{ Survivors of sudden cardiac death with presumed ischemia mediated VT } \\
\hline CABG & 1 & $\mathrm{~B}$ \\
\hline $\mathrm{PCl}$ & III: Harm & $\mathrm{B}$ \\
\hline \multicolumn{3}{|c|}{$\begin{array}{l}\text { *, In patients with multivessel disease who also have diabetes, it is reasonable to choose CABG (with LIMA) over PCI (class Ila; LOE: B). } \\
\text { CABG indicates coronary artery bypass graft; CAD, coronary artery disease; COPD, chronic obstructive pulmonary disease; COR, class } \\
\text { of recommendation; EF, ejection fraction; LAD, left anterior descending; LIMA, left internal mammary artery; LOE, level of evidence; LV, } \\
\text { left ventricular; N/A, not applicable; PCI, percutaneous coronary intervention; SIHD, stable ischemic heart disease; STEMI, ST-elevation } \\
\text { myocardial infarction; STS, Society of Thoracic Surgeons; SYNTAX, Synergy between Percutaneous Coronary Intervention with TAXUS } \\
\text { and Cardiac Surgery; TIMI, thrombolysis in myocardial infarction; UA/NSTEMI, unstable angina/non-ST-elevation myocardial infarction; } \\
\text { UPLM, unprotected left main disease; VT, ventricular tachycardia. }\end{array}$} \\
\hline
\end{tabular}

day standards. The rate of repeat revascularization with PCI in the SYNTAX trial was $13.5 \%$ at 12 months and $25.9 \%$ at 5 years. Moreover, the rate of definite or probable stent thrombosis was $3.3 \%$ at 12 months and $5.5 \%$ at 5 years. PCI has considerably advanced since the first generation DES era and studies have shown that the newer generation DES reduces restenosis, stent thrombosis, death or MI when compared with older generation DES or BMS $(13,14)$. The applicability of SYNTAX trial to contemporary practice of $\mathrm{PCI}$ is therefore debatable.

The BEST trial was subsequently designed to evaluate the comparative efficacy of CABG versus PCI with newer generation DES (everolimus eluting stent) in patients with multivessel disease (12). It was a prospective, openlabel, randomized trial evaluating the primary end point of composite of death, myocardial infarction, or target-vessel revascularization (MACCE) at two years. Assuming a $12 \%$ incidence of primary endpoint (MACCE) at 2 years with CABG and using a non-inferiority margin of $4 \%$, the trial had $80 \%$ power to detect non-inferiority between PCI and CABG with a sample size of 1,776 patients. However due to slow enrollment, the trial was prematurely terminated after only 880 patients. The achieved control event rate was $11 \%$ for CABG at 2 years. The results demonstrated no significant difference between PCI and CABG for the primary end point at 2 years $(11.0 \%$ vs. $7.9 \% ; \mathrm{P}=0.32)$. The authors concluded that PCI with everolimus-eluting stents was non-inferior to CABG. However, at long-term follow-up of 4.6 years, the primary end point occurred significantly more frequently with PCI (15.3\% vs. $10.6 \% ; \mathrm{P}=0.04)$, driven by higher rate of target-vessel revascularization in the PCI group $(7.1 \%$ vs. $3.8 \%$; $\mathrm{P}=0.03)$. There was no significant difference between the two groups for death (6.6\% vs. $5.0 \% ; \mathrm{P}=0.30)$ or $\mathrm{MI}(4.8 \%$ vs. $2.7 \% ; \mathrm{P}=0.10)$. Strengths of this trial are the use of contemporary DES and high usage of arterial grafts $(99.3 \%)$ with CABG. However, there are significant limitations of this study. The study enrolled less than $50 \%$ of intended target and thus is severely underpowered even for the composite primary outcome, let alone for the individual endpoints of death or for MI. Moreover, there was lower rates of complete revascularization with $\mathrm{PCI}$ when compared with $\mathrm{CABG}$ 


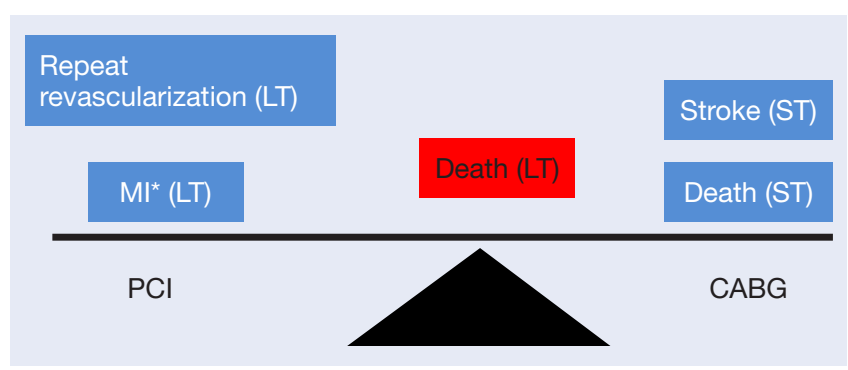

Figure 1 Choosing between percutaneous coronary intervention and coronary artery bypass graft surgery for nondiabetic patients with multivessel disease. ST, short term; LT, long term. *, in those with incomplete revascularization.

\section{(50.9\% vs. $71.5 \% ; \mathrm{P}<0.001)$}

Thus the above two studies were not powered for the outcome of death. Can combining the results of the above studies provide adequate power for the outcome of death? The authors in the current study attempted to do just that by a patient level analysis of the SYNTAX and BEST trial with the primary end point being all cause mortality. In this study, among 1,275 patients (638 in CABG arm and 637 in PCI arm) followed up for a median of 61 months, CABG resulted in significantly less number of deaths from any cause compared to PCI (6\% vs. 9.3\%; HR: $0.65 ; 95 \%$ CI: 0.43 to $0.98 ; \mathrm{P}=0.039$ ), cardiovascular death (HR: 0.41 ; 95\% CI: 0.25 to $0.78 ; \mathrm{P}=0.005$ ), MI (HR: $0.40 ; 95 \%$ CI: 0.24 to $0.65 ; \mathrm{P}<0.001$ ), and repeat revascularizations (HR: 0.55 ; 95\% CI: 0.40 to 0.75 ; $<<0.001)$. Although CABG had a higher rate of stroke than PCI, the difference was not statistically significant (HR: $1.13 ; 95 \%$ CI: 0.59 to 2.17; $\mathrm{P}=0.714$ ). When stratified by the SYNTAX score, there was no significant difference in patients with low SYNTAX score (0-22) for all-cause mortality (6\% vs. $7.5 \% ; \mathrm{P}=0.60)$. Whereas in patients with intermediate (23-32) to high $(\geq 33)$ SYNTAX scores mortality was significantly lower in the CABG group ( $7.1 \%$ vs. $11.6 \% ; \mathrm{P}=0.02)$.

Does this study provide ironclad evidence to support CABG instead of PCI for all nondiabetic patients with multivessel disease? Unfortunately the answer is a resounding no. The SYNTAX trial is no longer relevant to contemporary practice as multiple trials and Meta analyses have shown that Taxus stent is inferior to $2^{\text {nd }}$ generation DES. Although the BEST trial is relevant, the trial was severely underpowered even for the composite endpoint. Moreover, combining BEST and SYNTAX does not add to the $2^{\text {nd }}$ generation DES group.

In conclusion, while the authors aim to answer an important question, the combination of these two nonideal datasets (for reasons mentioned above), lends inherent limitations to interpretation of the results. So what evidence do we have while choosing the optimal revascularization strategy for our patients with multivessel CAD? Compared with the first-generation DES used in the SYNTAX study, second-generation DES have thinner struts, thinner and more biocompatible polymer which cause less inflammation and reduce the risk of restenosis and stent thrombosis by promoting faster vessel healing. As such, second generation DES have been shown to reduce the risk of death, MI, and stent thrombosis compared to bare metal and first generation DES (14-17). In this context, a well powered randomized trial comparing the best of CABG (complete revascularization with multi arterial grafts) versus best of PCI (complete functional revascularization with $2^{\text {nd }}$ generation DES) would ideally provide the relevant answer. In the absence of such a trial, data from non-randomized studies offer important insights-albeit being hypothesis generating only.

In a recent meta-analysis of 68 randomized trials with 24,015 diabetic patients CABG was compared to PCI with first and second generation DES (18). The results found that while first generation DES were associated with significantly increased mortality compared to CABG, second generation DES were not associated with a statistically significant increase in mortality, reflecting a diminishing mortality gap between PCI and CABG with contemporary stents. Moreover, analyses of data from New York State registries comparing PCI (angioplasty and first generation DES) with CABG have demonstrated superior survival with CABG (19-21). However, a propensity matched analysis of 18,446 patients comparing EES (second generation DES) versus CABG for multivessel CAD found similar risk of death among the two groups (3.1\% vs. $2.9 \%$; HR: 1.04 ; $95 \%$ CI: 0.93 to $1.17 ; \mathrm{P}=0.50$ ) at 2.9 years (22). Although PCI was associated with a significantly higher risk of $\mathrm{MI}$ (1.9\% vs. $1.1 \%$; HR: 1.51 ; $95 \%$ CI: 1.29 to 1.77 ; $\mathrm{P}<0.001)$ and repeat revascularization $(7.2 \%$ vs. $3.1 \%$; HR: 2.35; 95\% CI: 2.14 to 2.58 ; $\mathrm{P}<0.001)$, the PCI group had a significantly lower risk of stroke $(0.7 \%$ vs. $1.0 \%$ per year; HR: 0.62 ; $95 \%$ CI: 0.50 to 0.76 ; $\mathrm{P}<0.001)$. Additionally, the short-term outcomes (in hospital or $\leq 30$ days) favored PCI with lower risk of death (0.6\% vs. $1.1 \%$; HR: 0.49 ; $95 \%$ CI: 0.35 to $0.69 ; \mathrm{P}<0.001)$ and stroke $(0.2 \%$ vs. $1.2 \%$; HR: 0.18; 95\% CI: 0.11 to 0.29; $\mathrm{P}<0.001$ ) (Figure 1 ). Notably, in patients who underwent complete revascularization with PCI, there was no difference between PCI and CABG for 
MI. Based on the existing data it appears that with newer generation stents, the difference in mortality between PCI and CABG is perhaps narrowing. It should not be forgotten that with time, the surgical success and technique of CABG has also progressed. Thus, there is a dire need for adequately powered randomized trials comparing secondgeneration DES with CABG to evaluate the efficacy in the current era. Until then, careful decision should be made with a 'Heart-team' approach taking into account the patient characteristics, the anatomy of the lesions, ability to completely revascularize with PCI and patient preference.

\section{Acknowledgements}

None.

\section{Footnote}

Provenance: This is an invited Editorial commissioned by the Section Editor Feng Zhang (Department of Cardiology, Zhongshan Hospital of Fudan University, Shanghai, China). Conflicts of Interest: The authors have no conflicts of interest to declare.

Comment on: Ford I, Murray H, McCowan C, et al. Long-Term Safety and Efficacy of Lowering Low-Density Lipoprotein Cholesterol With Statin Therapy: 20-Year Follow-Up of West of Scotland Coronary Prevention Study. Circulation 2016;133:1073-80.

\section{References}

1. Goldstein JA, Demetriou D, Grines CL, et al. Multiple complex coronary plaques in patients with acute myocardial infarction. N Engl J Med 2000;343:915-22.

2. Ringqvist I, Fisher LD, Mock M, et al. Prognostic value of angiographic indices of coronary artery disease from the Coronary Artery Surgery Study (CASS). J Clin Invest 1983;71:1854-66.

3. Fihn SD, Blankenship JC, Alexander KP, et al. 2014 ACC/AHA/AATS/PCNA/SCAI/STS focused update of the guideline for the diagnosis and management of patients with stable ischemic heart disease: a report of the American College of Cardiology/American Heart Association Task Force on Practice Guidelines, and the American Association for Thoracic Surgery, Preventive Cardiovascular Nurses Association, Society for Cardiovascular Angiography and Interventions, and Society of Thoracic Surgeons. J Am Coll Cardiol 2014;64:1929-49.

4. Bavry AA, Kumbhani DJ, Rassi AN, et al. Benefit of early invasive therapy in acute coronary syndromes: a metaanalysis of contemporary randomized clinical trials. J Am Coll Cardiol 2006;48:1319-25.

5. BARI 2D Study Group, Frye RL, August P, et al. A randomized trial of therapies for type 2 diabetes and coronary artery disease. N Engl J Med 2009;360:2503-15.

6. De Bruyne B, Pijls NH, Kalesan B, et al. Fractional flow reserve-guided PCI versus medical therapy in stable coronary disease. N Engl J Med 2012;367:991-1001.

7. Boden WE, O'Rourke RA, Teo KK, et al. Optimal medical therapy with or without PCI for stable coronary disease. N Engl J Med 2007;356:1503-16.

8. Pursnani S, Korley F, Gopaul R, et al. Percutaneous coronary intervention versus optimal medical therapy in stable coronary artery disease: a systematic review and meta-analysis of randomized clinical trials. Circ Cardiovasc Interv $2012 ; 5: 476-90$.

9. Farkouh ME, Domanski M, Sleeper LA, et al. Strategies for multivessel revascularization in patients with diabetes. N Engl J Med 2012;367:2375-84.

10. Chang M, Ahn JM, Lee CW, et al. Long-Term Mortality After Coronary Revascularization in Nondiabetic Patients With Multivessel Disease. J Am Coll Cardiol 2016;68:29-36.

11. Serruys PW, Morice MC, Kappetein AP, et al. Percutaneous coronary intervention versus coronary-artery bypass grafting for severe coronary artery disease. N Engl J Med 2009;360:961-72.

12. Park SJ, Ahn JM, Kim YH, et al. Trial of everolimuseluting stents or bypass surgery for coronary disease. $\mathrm{N}$ Engl J Med 2015;372:1204-12.

13. Bangalore S, Kumar S, Fusaro M, et al. Outcomes with various drug eluting or bare metal stents in patients with diabetes mellitus: mixed treatment comparison analysis of 22,844 patient years of follow-up from randomised trials. BMJ 2012;345:e5170.

14. Bangalore S, Toklu B, Amoroso N, et al. Bare metal stents, durable polymer drug eluting stents, and biodegradable polymer drug eluting stents for coronary artery disease: mixed treatment comparison meta-analysis. BMJ 2013;347:f6625.

15. Sabate M, Cequier A, Iñiguez A, et al. Everolimus-eluting stent versus bare-metal stent in ST-segment elevation myocardial infarction (EXAMINATION): 1 year results of a randomised controlled trial. Lancet 2012;380:1482-90. 
16. Sarno G, Lagerqvist B, Fröbert O, et al. Lower risk of stent thrombosis and restenosis with unrestricted use of 'new-generation' drug-eluting stents: a report from the nationwide Swedish Coronary Angiography and Angioplasty Registry (SCAAR). Eur Heart J 2012;33:606-13.

17. Valgimigli M, Tebaldi M, Borghesi M, et al. Two-year outcomes after first- or second-generation drug-eluting or bare-metal stent implantation in all-comer patients undergoing percutaneous coronary intervention: a prespecified analysis from the PRODIGY study (PROlonging Dual Antiplatelet Treatment After Grading stent-induced Intimal hyperplasia studY). JACC Cardiovasc Interv 2014;7:20-8.

18. Bangalore S, Toklu B, Feit F. Outcomes with coronary artery bypass graft surgery versus percutaneous coronary intervention for patients with diabetes mellitus: can newer generation drug-eluting stents bridge the gap? Circ Cardiovasc Interv 2014;7:518-25.

19. Hannan EL, Racz MJ, McCallister BD, et al. A comparison of three-year survival after coronary artery bypass graft surgery and percutaneous transluminal coronary angioplasty. J Am Coll Cardiol 1999;33:63-72.

20. Hannan EL, Racz MJ, Walford G, et al. Long-term outcomes of coronary-artery bypass grafting versus stent implantation. N Engl J Med 2005;352:2174-83.

21. Hannan EL, Wu C, Walford G, et al. Drug-eluting stents vs. coronary-artery bypass grafting in multivessel coronary disease. N Engl J Med 2008;358:331-41.

22. Bangalore S, Blecker S, Hannan EL. Everolimus-Eluting Stents or Bypass Surgery for Coronary Disease. N Engl J Med 2015;373:582.
Cite this article as: Dwivedi A, Bangalore S. Choosing between percutaneous coronary intervention and coronary artery bypass graft surgery for nondiabetic patients with multivessel disease. J Thorac Dis 2016;8(11):3028-3033. doi: 10.21037/jtd.2016.11.104 